\title{
Exposição do Director da Faculdade de Direito de 5. Paulo ao Conselho Superior de Ensino na Sessão Periodica de Agosto de 1913.
}

\section{Illms. Exms. Snzs.}

$\mathrm{O}$ art. I4 da Lei n. 2738 de 4 de Janeiro do corrente anno, fixando a despeza geral da Republica para o corrente exercicio, contém a seguinte disposição: «O Poder Executivo remetterá ao Congresso, em sua proxima reunião, um balanço dos patrimonios dos diversos estabelecimentos de ensino, actualmente subvencionados, indicando as bases que the parecerem mais convenientes para a sua completa desofficialisação».

Esse artigo importa fatalmente as seguintes consequencias :

I. ${ }^{\circ}$ - Que esta Faculdade, assim como todos os Institutos que a propria Lei Organica, art. $3 .^{\circ}$, ao contrario do Aviso de 28 de Setembro de I9II, denomina "Institutos Federaes de Ensino Superior e Fundamental», assim como não está desofficialisada no organismo e no funccionamento, tarnbem não está desofficialisada nas condições de vida (receita e despesa;

2. - Que a attribuição de um patrimonio a estes Institutos é feita, não em um sentido proprio, mas em um sentido analogico, visto que tal patrimonio consiste: a) nas taxas creadas especificamente pela Lei Organica, para serem lançadas pelas congregações de professores sobre os estudantes, com applicação ao destino determinado pelo art. $90^{\circ}$ da mesma Lei Organica; b) em uma 
verba da despesa geral do Estado, a titulo de subvenção, posto que consignada a pagamento de vencimentos arbitrados por lei do Estado, para cargos e empregos creados por lei do Estado, exercidos por funccionarios providos pelo mesmo Estado e com funcções especificadas por lei do mesmo Esstado.

$3 .^{\circ}$ - Que o Conselho Superior do Ensino não «succede o Esstado; a propria Lei Organica diz «substitue a acção fiscal do Estado»; a substituição suppõe a permanencia do substituido, que só por impedimento ou por delegação, deixa de exercer a acção; em summa, o Conselho Superior do Ensino é substituto do Esstado por simples delegação da Lei Organica.

$4 .^{\circ}$ - Que, portanto, as condições de vida desta Faculdade, isto é, a sua receita e despesa, jámais podem deixar de ser subordinadas á acção do Estado, estabelecendo elle proprio, e portanto officialmente, o plano da conversão da receita especial dos Institutos, segundo as bases que ao Governo parecerem convenientes para a pretendida desofficialisação.

$5^{\circ}$ - Que, mesmo sob o ponto de vista da receita especial dos Institutos, estes ainda não estão desofficialisados, visto que, para dar fórma a esta receita, dependem do Governo e do Congresso Nacional.

Desde que a constituição e a applicação da receita terão fatalmente de subordinar-se, em suas linhas essenciaes, ao plano que fôr officialınente estabelecido, esse patrimonio nada mais é do que a receita consignada para uma fundação creada pelo Esstado em virtude da Constituição e de uma Lei ordinaria; constituida pelo Estado, em virtude de uma Lei ordinaria, quer na indicação dos orgams, quer na especificação das funcções; conservada pelo Estado na determinação de seus meios de vida (receita e despesa); fiscalisada pelo Estado, ainda em virtude de uma Lei ordinaria, quer no movimento ge- 
ral dos orgams, quer na effectividade e regularidade das funcções, quer na consignação e obsignação da receita e da despesa.

\section{TITULO I}

DeTERMINAÇÃo DA RECETTA

A realidade positiva é que esta Faculdade ainda vive como fundação creada pelo Estado, que, mesmo em virtude do art. I4 da citada Lei n. $273^{8}$ de 4 de Janeiro do corrente anno, provê á sua conservação; mas, para tanto quanto possivel, corresponder á pretenção desofficialisadora, cumprimos o dever de analysar a receita desta Faculdade, dividindo-a em tres classes:

r. ${ }^{a}$ Receita proveniente da Lei geral do orçamento;

2. ${ }^{2}$ Receita proveniente das taxas creadas pela Lei Organica;

$3 \cdot{ }^{\text {a }}$ Receita proveniente de doações e legados.

\section{CAPITULO I}

RéCEITA PROVENIENTE DA LEI GERAL DO ORÇAMENTO

\section{Secção I}

As subvenções votadas Pelo CONGResso Nacional

$\mathrm{O}$ art. I26 § unico da Lei Organica assim dispõe:

«Das subvenções votadas pelo Congresso Nacional e entregues aos Institutos de Ensino, será deduzida a parte referente aos actuaes docentes e funccionarios (isto é, aos nomeados antes de $j$ de Abril de igrI), que continuarão a receber os seus vencimentos no Thesouro $\mathrm{Na}$ cional». 
Eiste texto estabelece a supposição de que a verba - Subvenção - é totalmente entregue aos Institutos, para depois ser deduzida a parte referente aos docentes e funccionarios nomeados antes da Lei Organica; mas, esta. deducção é feita antes da entrega, como resulta do art. I27, assim concebido:

«Os docentes e funccionarios, nomeados na vigencia do regimen escolar creado pela presente lei, receberão os seus vencimentos na thesouraria do Instituto a que pertencerem. Para este effeito e demais despezas, o Governo entregará aos Institutos de ensino, emquanto os patrimonios delles não bastarem á satisfaç̧ão das necessidades materiaes e pedagogicas, e sob o titulo de subvenção, as. quantias necessarias e votadas em lei».

O Thesoureiro desta Faculdade, portanto, só é obsignatario da parte consignada aos docentes e funccionarios nomeados na vigencia da Lei Organica; a obsignação da outra parte é feita na Delegacia Fiscal. Estas obsignações, feitas de accordo com as leis que fixam os vencimentos, estão subordinadas á averbação correspondente aos titulos de nomeação e aos nomes dos respectivos docentes e funccionarios, afim de poder ser fiscalisada a effectividade das respectivas soluções ou pagamentos. receita.

Mas, entremos logo na enumeração desta parte da

\section{Exercicio de IgII}

Pelo officio de 23 de Abril, o Ministerio dos Negocios Interiores declarou a esta Directoria que mandára entregar, para pagamento das despesas dos mezes de Janeiro a Abril — 20:767\$664 á thesouraria desta Faculdade, sendo:

I $: 7$ I 3332 para o pessoal docente e administrativo; 3:200\$ooo para o pessoal stm nomeação; $5: 833 \$ 332$ para o material. 
Mas, essa quóta só foi recebida no dia 6 de Julho e na importancia de I3:566\$664.

Por officio de 27 de Junho, o mesmo Ministerio declarou ter requisitado a quóta de Io:383\$332, para occorrer, sempre de accordo com a demonstraęão que acompanhou o Aviso de 23 de Abril, ás despesas nos mezes de Maio e Junho, sendo:

5:866\$666 para o pessoal docente e administrativo;

I:600\$00o para o pessoal sem nomeação;

2:916\$666 para o material.

Mas, essa quóta só foi recebida no dia 30 de Julho e na importancia de $8: 583 \$ 332$.

Por officio de 23 de Agosto, o Ministerio declarou ter requisitado a quóta de $10: 383 \$ 332$, para as despesas dos mezes de Julho e Agosto, sendo:

5:866\$666 para o pessoal docente e administrativo 1:600\$ooo para o pessoal sem nomeaçâo;

2:9r6\$666 para o material.

Esta quóta foi integralmente recebida no dia 30 de Dezembro.

Porém, foi, em 23 de Dezembro, declarado que o Ministerio da Justiça e Negocios Interiores havia requisitado o credito de 20:7666 $\$ 664$, que deveria ser entregue, como foi, ao Thesoureiro desta Faculdade, para as despesas com o pessoal docente e administrativo, com o pessoal sem nomeação e com o material, nos mezes de Setembro a Dezembro.

Esta quóta, que foi recebida inteira em Fevereiro deste anno, não veio discriminada; mas devemos calcular em:

II:7 I 3332 para o pessoal docente e administrativo; 3:200\$ooo para o pessoal sem nomeação; $5: 853 \$ 332$ para o material. 


\section{$-230-$}

Exercicio de 1912

O credito distribuido para I9I2 foi o seguinte:

Pessoal docente e administrativo . . 36:799\$996

Pessoal sem nomeação . . . 9:600\$0oo.

Material

Total . $\quad \frac{\mathrm{r} 7: 499 \$ 996}{63: 899 \$ 992}$

A relação annexa ao officio de 23 de Abril de I9ra contém o seguinte calculo:

Quatro professores extraordinarios

inclusive os 2 vagos 24:000\$000

Pessoal administrativo e dois be-

deis.

Pessoal sem nomeação

Material. .

$$
\begin{array}{ccc}
\cdot & \frac{\mathrm{II}: 200 \$ 000}{9: 600 \$ 000} & 35: 200 \$ 000 \\
\text { Total. } & \frac{17: 500 \$ 000}{\cdot} \cdot \underline{27: 100 \$ 000} \\
\hline 62: 300 \$ 000 \\
\hline
\end{array}
$$

Tendo sido nomeado ordinario um dos novos professores extraordinarios, foi alterado este calculo; e por isso é que o total se elevou a 63:899\$992.

Mas deste total a thesouraria desta Faculdade recebeu apenas rs. $54: 899 \$ 992$, porque a Delegacia Fiscal descontou os vencimentos de dois professores extraordinarios. nos mezes de Janeiro, Fevereiro, Março, Abril e Maio (51:000 $\$ 000)$ e os salarios dos serventes nesses mesmos. mezes (4:00o\$ovo), os quaes já tinham sido individualmente pagos na Delegacia Fiscal.

Por isso as quótas bimestraes differem assim:... $6: 783 \$ 332$ cada uma das de Janeiro e Fevereiro e de Março e Abril; 8:583\$322 a de Maio e Junho; I0:383\$332 as de Julho e Agosto e de Setembro e Outubro; a de Novembro e Dezembro é de Ir:983\$332, porque accresceu um professor ordinario, então nomeado na vaga do $\mathrm{Dr}$. Dino Bueno, que se jubilára. 
Em consequencia, para o pessoal de nomeação, conforme a demonstração do Thesoureiro desta Faculdade, só foi recebida aqui a quantia de Rs. 3r:799\$996, da qual, tendo sido applicada apenas a quantia de rs. 21:549\$978, resta um saldo de I0:350\$0I8.

\section{Exercicio de 1913}

As quótas bimestraes foram de $14: 439 \$ 000$ cada uma, das quaes até 30 de Junho foram recebidas tres. Total - 43:3 $17 \$ 000$.

Eis a distribuição para os tres bimestres:

Pessoal docente e administrativo 29:767\$002

Pessoal sem nomeação . . . . 4:800\$000

Material

$8: 749 \$ 998$

\section{Secção II}

\section{O E D F I C I O}

O edificio em que funcciona a Faculdade é, como se sabe, o antigo mosteiro de S. Francisco, cedido ao Estado para nelle funccionar uma fundação do mesmo Estado.

Seja considerado como uma constituição do direito real de uso, a verdade é que não póde o Estado cedel-o a outra personalidade. O edificio foi cedido ao Estado para uma fundação do mesmo Esstado; ora, como é corrente em Direito, o direito real de uso é indivisivel e incessivel (Confira-se Lafayette, Dir. das Cousas, I, $\S$ i 2 , n. 5). Portanto, si o Estado deixasse de usar para uma fundação official, a consequencia seria a consolidação do dominio da Orảem de S. Francisco.

Em todo o caso, qualquer que seja a hypothese, o edificio nunca póde entrar no patrimonio de uma fundadação privada, porque a propria Lei Organica declara que 
os edificios, em que funccionam os Institutos creados pela lei, continuam, como aliás não podem deixar de continuar, na "propriedade do Estado».

\section{Secção III}

O MATERIAL

A Lei Organica attribue ao patrimonio dos Institutos federaes, «o material de ensino, laboratorios, bibliothecas e o que para elles fôr adquirido».

E' outra analogia; mas, não é novidade. Na Italia, em situação analoga, o Governo recorreu a uma consulta, isto é, a um parecer do Conselho de Estado, que fez esta distincção: ha bens proprios das Universidades, mas para administração inherente; ha bens que, estando nas Universidades para uso da administração publica, não podem deixar de ser sujeitos á acção directa do Governo. (Confira-se MEucci, Dirit. Amminis., pag. I78). Esta distincção mereceu commentarios e satyras; mas, serviu de base para a Lei italiana de 22 de Abril de 1869 sobre a contabilidade do Estado.

Nós temos disposições legaes regulando este caso. Estas disposições estão consolidadas nos arts. 328 e seguintes do Decr. n. $775^{1}$ de 23 de Dezembro de I909, que, dando regulamento ao Thesouro Nacional e declarando que não ha contabilidades autonomas nos outros Ministerios, estabeleceu estas regras:

I. O material divide-se em material de consumo, material de transformação, material permanente, (art. 328) além do material de serviços industriaes (art. 338).

2. Quanto ao material de consumo e ao material de transformação, a Directoria de Contabilidade do Thesouro póde exigir dos almoxarifes e quaesquer funccionarios que o tiverem sob sua guarda, qualquer que seja o ministerio, demonstrações do seu emprego e utilisação (art. 329.) 
$3 .^{\circ}$ Quanto ao material permanente, esse fica sob a administração do ministerio em que é utilisado (art. $33^{2}$.

4..$^{\circ}$ Relativamente ao material de consumo e ao material de transformação, as directorias e secções de contabilidade dos diversos ministerios, assim como as repartições em que existirem esses materiaes, hão de se subordinar aos dispositivos da contabilidade fiscal, não só em relação á escripturação do movimento, como a inventarios (art. 330 e $33 \mathrm{I}$ ).

$5^{\circ}$ - Relativamente ao material permanente, o ministerio, em que é utilisado, está obrigado a enviar copia dos inventarios á Directoria do Patrimonio do Thesouro (art. 333 e seguintes).

6. - Quanto ao material das repartições de serviços industriaes da Republica (taes como correios e telegraphos, estradas de ferro, portos de mar, fabricas de polvora, institutos de ensino, etc.), - tudo isto será modelado de accordo com os actos regulamentares dos respetivos serviços, que, em todo o caso, diz o Decreto, «sempre se ajustarão ao regimen de inspecção e centralisação estabelecido na Lei n. 2083-de 30 de Julho de I909 e neste regulamento» (arts. 338 e seguintes)

Estamos reproduzindo estas regras, isto é, estes textos legaes até hoje não derogados,- para tornar bem sensivel que, na realidade, nem mesmo o material desta Faculdade póde ser desviado do patrimonio do Estado.

\section{CAPITULO II}

RECEITA PROVENIENTE DAS TAXAS DA LEI ORganica

O Conselbo Superior, na sua primeira reunião, já teve de reconhecer o seguinte:

I. Q Que a Lei Organica conferiu ás Congregações a attribuição não de crear taxas, mas a de lançar taxas, suppondo assim taxas já especificamente creadas; 
$2 .^{\circ}$ - Que a Lei Organica especificou as seguintes taxas :

a) Taxa de matricula;

b) Taxa de certidão;

c) Taxa de bibliotheca;

d) Taxa de certificados,

e) Taxa de frequencia de cursos;

f) Taxa de inscripção para exames.

$3 .^{\circ}$ - Que tratando-se de contribuições arbitraveis, como a da especie contida na Lei Organica, a taxação autonoma das Congregações, como todas as taxações antonomas de serviços publicos de analoga natureza, dependem da approvação do Governo, mediante a revisão do Conselho Superior, no exercicio da funç̧ão fiscal que the confere o art. $5^{\circ}$ da mesma Lei.

$\mathrm{O}$ acto dos estudantes, pagando as taxas ao Thesoureiro desta Faculdade, reveste a figura juridica da obsignatio, descripta no Codigo de Justiniano, Liv. VIII, tit. 43 , L. 9 ; porque, em relação aos estudantes, a thesouraria da Faculdade nada mais é do que o lugar determinado pela lei, para o pagamento do que elles devem ao instituidor da fundaşão, isto é, ao fundador, que é o. Estado Federal.

A propria Lei Organica se incumbe de affirmar que "por força da mesma Lei Organica», essas taxas «revertem; isto é, a Lei Organica tira as taxas da receita «ordinaria» da Fazenda Federal, não para desistir dellas, mas para que «revertam», isto é, para que a administração da Faculdade as appliquem ás necessidades materiaes e pedagogicas do instituto, cujas funcções a mesma Lei especifica e distribue.

A consequencia fatal é que a Faculdade, recebendo estas taxas, não as percebe como directa credora dos estudantes, mas como obsignataria de uma «receita especial» do Estado Federal, que é o credor. 
Mas, vejamos em quanto importaram essas taxas em cada um dos exercicios de I9II e I9I2 e no primeiro semestre de I9r3.

\section{Taxa de matricula}

No exercicio de I9II

$200 \$ 000$

No exercicio de I9I2 $20: 230 \$ 000$

No exercicio de I9I3 r6:660\$000

$$
\text { Total . 37:090\$000 }
$$

\section{Taxa de certidôes e certificados}

No exercicio de I9I I

7 II $\$ 900$

No exercicio de I9r 2

$6: 254 \$ 219$

No exercicio de I9I3 $3: 659 \$ 600$

Total . I0:625\$719

Essta Faculdade ainda não tem podido arrecadar as taxas de «certificado», porque ainda estão completando o curso apenas os estudantes do Codigo de Ensino. Ora, a estes não é licito recusar o diploma de bacharel, que já paga a taxa de sello de $\mathbf{2 6} \$ 500$, a que se refere o Decr. de 22 de Janeiro de $1900, \$ 8 .^{\circ}$ da tabella $B$. O sello não póde ser dispensado, sob pena de incorrer esta Directoria na multa de 600\$000 a 2:000\$000, na forma do art. 63 do citado Decreto de 22 de Janeiro de I90o. Não estando revogado este decreto, não podendo esta Directoria recusar o diploma, nem concorrer para fraudar o fisco, maximè the resultando d'ahi aquella multa, não é possivel cobrar dos estudantes essa taxa de «certificado», emquanto a Fazenda considerar o diploma de bacharel como um titulo de direito e sujeital-o ao sello de verba.

\section{Taxa de frequencia}

No exercicio de I9II

Nihil

No exercicio de I9I2 ro:080\$000

No exercicio de r9I3 
Taxa de inscripcão para exames

No exercicio de I9II

I 5:500\$000

No exercicio de I9I2 . . . . 28:300\$000

No exercicio de I9I3 . : . . 3:650\$000

Totál . . $\overline{47: 450 \$ 000}$

A Congregação não lançou taxas de bibliotheca; e, quanto á da inscripção para o exame de admissão, resultou :

No exercicio de IgII

$$
\begin{array}{cc}
\text {. } & \text { Nihil } \\
\text {. } & 3: 920 \$ 000 \\
\text {. } & \text { 10:840\$000 }
\end{array}
$$

No exercicio de Igra

No exercicio de I9I3

Total

Depois que tivermos exposto a applicabilidade á despeza, veremos que destas taxas sómente serão convertiveis em titulos os productos das taxas de matricula e de certidões e as porcentagens das taxas de frequencia e de inscripção para exame.

A Lei Organica refere-se, no art. $7 .^{\circ}$ letra $f$, a porcentagens das taxas de frequencia e das taxas de inscripção para exames; e, no art. 98, determina entre as attribuições do Thesoureiro (letras $h$ e $j$, ) não só receber as taxas, como «descontar as porcentagens devidas á administração».

Não é liquido que estas porcentagens sejam destinadas á conversão. Do espirito da Lei se deduz que são destinadas ao serviço administrativo. Mas, estando este remunerado pelo Estado, não ha inconveniente em aproveital-as para o plano da conversão.

O Regulamento expedido com o Decr. n. 8662 de 5 de Abril de I9II, art. I6, marca, para esta porcentagem, a taxa de $5 \%$; mas, o Conselho Superior mandou deduzir Io \%. Feita esta deducção, o resultado será este:

Das taxas de frequencia . . . . 2:370\$000

Das taxas de inscripçâo para exames $\quad 4: 745 \$ 000$

Dos exames de admissão . . . . . $1: 476 \$ 000$

Total . $8: 591 \$ 000$ 


\section{CAPITUIO III}

\section{DOAÇÕES E LEGADOS}

A Congregação desta Faculdade aceitou a missão de realizar os designios dos doadores das seguintes doações:

r. ${ }^{\circ}$ - Premio - Duarte de Azevedo: é fundado em dez apolices da divida publica do Estado de S. Paulo, da $9 .^{2}$ série, do valor de um conto de réis cada uma, representadas por uma cautela provisoria sob. n. 355;

$2 .^{\circ}$ - Premio -- Rodrigues Alves: é fundado em treze apolices da divida publica desse mesmo Estado, da mesma. série. do mesmo valor cada uma, representadas pela cautela. provisoria n. 376 .

A personalidade já está nessas mesmas doações, das. quaes esta Faculdade não é propriamente donataria, mas, por sua Congregação de Professores, simples obsignataria em proveito dos destinatarios, isto é, dos estudantes merecedores do premio, estudantes estes que são os verdadeiros donatarios. Esses Premios, já por sí, constituem fundações, com personalidade propria, sujeitas, como qualquer outra fundação ou acto de irrevogavel vontade, á. fiscalização do Estado, ou mediante a acção administrativa directa, ou mediante a acção judiciaria pelo Juizo da Provedoria.

O direito de receber doações e legados, por si só, não confere ás fundações do Estado uma personalidade diversa; dá-se aqui o mesmo phenomeno que o Direito Romano, nas Inst., L. IV, tit. VII, quod cum eo, qui in. aliena protestate est, negotium gestum esse dicitur. Os proprios escravos podiam receber doações e legados, desdeque o senhor nisso consentisse; e, então, o senhor era obrigado a todos os encargos resultantes da doação, quia. is qu ita contrahit, fidem domini sequi videtur. Quem faz uma doação á Fiaculdade de Direito de S. Paulo, tem contra o Estado acção analoga ás acções institoria e ou- 
tras em que o preponente responde por actos do preposto: si eu doar á Faculdade uma quantia para um fim didactico, e si a administração da Faculdade não a applicar a este fim, a minha acção é a institoria contra o Estado Federal, visto que não considero a Faculdade sinão ad instar de uma proposta do Estado para a acção da diffusão do ensino juridico. Em summa, a personalidade fica sempre no Estado, quer para os direitos, quer para as obrigações contrahidas; e, assim, na realidade, essas doações não entram no patrimonio da Faculdade, visto que, por si mesmas, constituen uma fundação, a cargo de outra fundação; essa outra fundação é responsavel pelo cumprimento da intenção dos doadores; ora, como o instituidor dessa fundação cumpridôra é o Estado, do qual a Congregação é simples mandataria, a responsabilidade pela realisação dos designios dos doadores é toda do Estado. Como diriam os jurisconsultos inglezes, o trustee dessas doações é o Estado, que opera, como diriam os Romanos, ad instar de um fiduciario.

Ha ainda doações de livros á Bibliotheca, livros que, por serem destinados á leitura dos estudantes, estão incorporados ao restante material da Bibliotheca.

\section{TITULO II}

APPliCARILIDADE E APPLICAÇÃO DA RECEITA

Não temos necessidade de lembrar a applicabilidade do edificio e do material dos Institutos, assim como a das doações e legados; mas, temos necessidade de despertar a attenção para a applicabilidade da denominada-subvenção-e das taxas.

\section{CAPITULO I}

A APPLICABILIDADE DA «SUBVENÇÃO»

Essta verba é destinada ao pessoal docente e administrativo, ao pessoal sem nomeação, e ao material. 
Em relação ao pessoal docente e administrativo destes Institutos, o mandato para pagar não é generico, visto que a lei individúa os orgams, especifica as funcções, determina-1hes as condições de investidura e de exercicio e enumera os vencimentos annuaes para cada cargo ou emprego; por isso é que cada um desses vencimentos, em relação a cada cargo, constitue individualmente titulo peculiar de despesa e, como tal, não póde deixar de ser averbado, não só em seguida á posse do respectivo funccionario, como em cada exercicio financeiro.

As leis fiscaes, desde o Alvará de 28 de Junho de 1808 até o Decreto n. ${ }^{\circ} 7.75^{\mathrm{I}}$ de 23 de Dezembro de 1909 , não admittem sobre estes pontos tergiversação alguma; e, por isso, declarei ao Thesoureiro desta Faculdade:

I. Que, comquanto a verba tenha denominą̧̃ão generica de subvenção, ella contém virtualmente uma distribuição legalmente fixada de consignações, visto que é para pagamento de obrigações incommunicaveis do Estado Federal, singularmente determinadas na qualidade e na quantidade, a individuos singularmente caracterisados, não só pelos cargos e empregos que exercern, como até pela quota de vencimentos, na forma da lei;

2..$^{\circ}$ Que os vencimentos são arbitrados pelo proprio Estado Federal, para "cada um» dos cargos ou empregos, de sorte que, seja como fôr, o pagamento é feito discriminadamente a cada um dos funccionarios que exercem cada um desses cargos ou empregos;

$3 .^{\circ}$ Que si, por contemporisação, cada um desses vencimentos não tem sido averbado, segundo esta discriminação, na Delegacia Fiscal do Thesouro Nacional, essa irregularidade não desnatura a consignação fatalmente individual a cada um dos funccionarios que exercem os cargos ou empregos, individuados não só pela disposição da lei que os creou, como até pela quota de vencimentos que, na forma da lei, compete aos nomeados; 
$4 .^{\circ}$ Que, sendo o Thesoureiro desta Faculdade pagador de consignações do Estado Federal, está fiscalmente responsavel perante o Thesouro Nacional;

$5^{\circ}$ Que a Fazenda Nacional, portanto, ha de, mais cedo ou mais tarde, reclamar a restituição de tudo que, da subvenção, não tenha sido applicado ao fim peculiar determinado pelo artigo I 27 da Lei Organica, isto é, ao pagamento desses individuos, visto não ser licito desviar uma consignação taxativamente fixada pelas leis ns. I500 de I de Setembro de r 906 e outras, nem evitar a discriminação individual determinada pelas leis fiscaes (arts. 3 r8 e 326 do Decr. n. $775^{x}$ de 23 de Dezembro de 1909).

O Thesoureiro desta Faculdade, funccionario escrupuloso e correctissimo, tem a sua escripturação moldada segundo os regulamentos fiscaes, pois:

r. - Que, como é natural, logico e regular, a folha de vencimentos é formulada «completa» com «todo»o pessoal, conforme expressa disposição da Lei Organica, e conforme é fiscalmente necessario para comparação das substituições e verificação do exercicio;

2. - - Que a obrigação do Estado para com o pessoal novo é tão unica, tão indivisivel, tão incommunicavel, como a obrigação para com o pessoal antigo;

$3 .^{\circ}$ - Que, na forma das leis fiscaes, desde o Alvará de 28 de Junho de 1808 até o Decr. n. 775 I de 23 de Dezembro de I909, está expressamente firmado o principia de que «a contabilidade, a situação do pessoal activo e inactivo, é subordinada á consignação dos creditos para pagamento dos vencimentos, pagamento que a Directoria Geral de Contabilidade compete regular e superintender»;

$4 .^{\circ}$ - Que os vencimentos dos professores nomeados na vigencia da Lei Organica são os mesmos numerados pela Lei n. 1500 de I de Setembro de I906; entretanto, em conflicto com as leis fiscaes, especialmente com os arts. 
3I8, 322, 324 do Decr. n. 775I de 23 de Dezembro de I909, não obstante as minhas constantes representações, insistese em scindir a verba denominada subvenção em duas partes, para ser o pessoal antigo pago na pagadoria da Delegacia Fiscal e o pessoal novo pago na Thesouraria desta Faculdade;

$5 .^{\circ}$ - Que, para minorar os effeitos da perturbação que, mais cedo ou mais tarde, possa provir desse desvio das regras da contabilidade fiscal, a Thesouraria desta Faculdade modelou o seu livro pelo da Delegacia Fiscal do Thesouro Nacional, dividindo-o em columnas, na forma dos artigos 318 e seguintes do Decreto n. 7.75 de 23 de Dezembro de I909, isto é :

a) com as discriminações do pessoal;

b) com as discriminações dos vencimentos, conforme as leis e as tabellas;

c) com as consignações correspondentes ás leis e ás tabellas e constituindo titulos de despeza;

d) com o desconto do imposto do sello da nomeação e do imposto sobre vencimentos, não só porque foi isso deliberado pelo Conselho Superior do Ensino, como porque, na forma do Decreto n. 7.544, de 22 de Novembro de I879, artigo I. ${ }^{\circ}$, paragrapho $2 .^{\circ}$, são sujeitos ao imposto os vencimentos que dos cofres publicos geraes perceberem, "por qualquer titulo», o prissoal activo e o inactivo;

e) com observações ou outras averbações.

Segundo resulta da demonstração do Thesoureiro, o saldo ou sobra da subvenção obsignada na Thesouraria desta Faculdade, consignada ao pessoal docente e administrativo nomeado na vigencia da Lei Organica, é:

No exercicio de IgII

No exercicio de I9I2

$4 \$ 865$

No primeiro semestre de I9I 3

I0:250\$0I 8

9:248\$257 
Não me parece que estes saldos, uma vez liquidados, possam deixar de ser devolvidos ao Thesouro Nacional; em todo o caso, o Thesoureiro desta Faculdade fez uma consulta á Delegacia Fiscal e requisitou que esta pedisse solução ao Ministerio da Fazenda (officios annexos). Esta consulta ainda não teve solução.

Quanto ao pessoal sem nomeação, o saldo é minimo; visto que decorre apenas dos pontos por faltas de comparecimento.

Quanto ao material, não ha saldo até hoje verificado, visto que é para objectos de expediente, livros, jornaes, encadernações, etc., illurninação, impressões, etc., e toda a quota tem sido empregada, conforme as demonstrações nas contas em tres vias, tudo na fórma dos regulamentos fiscaes.

\section{CAPITULO II}

\section{Applicação do producto das taxas}

As taxas de matricula e de certidões, assim como as porcentagens das taxas de frequencia e de inscripção para exames, estão intactas. Passemos a ver como esta Faculdade tem applicado o saldo das taxas de frequencia e de inscripção para exames.

O saldo das taxas de frequencia não tem aproveitado aos professores antigos, porque todos estes, por maior que possa ser a vantagem dessas taxas, declaram preferir manter o seu direito a addicionaes na proporção do seu tempo de exercicio (art. I28 § unico da Lei Organica); não tem sido applicado aos professores novos, porque não está bem definido o destino dessas taxas. A principio, entendeu-se que os novos professores só tem direito á participar das taxas de frequencia na razão do tempo de exercicio e na mesma proporção em que aos antigos são conferidas as gratificações addicionaes; e isto era dedu- 
zido do espirito do art. I 28 \& unico da Lei Organica. Porém, pelo que resolveu o Conselho Superior, na sessão de 19 de Fevereiro de I9I2, o saldo dessas taxas pertencem respectivamente aos professores; salvo a parte correspondente aos cursos geraes dos professores antigos, que hajam optado pelas gratificações addicionaes. Entretanto, devo declarar que até hoje, nesta Faculdade, ninguem reclamou participar dellas.

O saldo das taxas de inscripção para exame tambem não tinham o destino perfeitamente definido; aliás, ellas não são uma taxa novamente creada, visto que já era percebida no regimen anterior como pertencente á receita geral da Fazenda. O Conselho Superior, nessa mesma resolução de I9 de Fevereiro de I9ı2, decidiu: I. ${ }^{\circ}$ Que as taxas de exame, pagas pelos alumnos que estudam sob o regimen do antigo Codigo de Ensino, revertem para o patrimonio do respectivo instituto; $2 .^{\circ}$ Que as taxas de exames, pagas pelos alumnos que estudam sob o regimen da Lei Organica, devem ser distribuidas integralmente por todos os examinadores de cada materia, na proporção do exame em que tenham tomado parte, não cabendo porcentagem alguma aos funccionarios da administração. Entretanto, devo tambem declarar que, nesta Faculdade ninguem reclamou participar dellas.

Ora, o Aviso n. 4I I de 26 de Março de I9I2 estabeleceu a doutrina de que deve correr pelo producto das taxas qualquer despeza por serviço não contido no credito ordinario da verba-Subvenção. Em consequencia desse Aviso, teve de correr pelas taxas: $I^{\circ} \mathrm{O}$ pagamento dos vencimentos do professor que substituiu o dr. José Bonifacio de Oliveira Coutinho, que se achava em commissão do Governo, durante os mezes de Julho a Outubro de I9II; $2 .^{\circ} \mathrm{O}$ pagamento dos professores de outras secções que accumularam, nas aulas dos alumnos da segunda serie, as cadeiras de Economia Politica e de Direito Administrativo, visto que, por deliberação da Congregação e por necessidades 
da disciplina, foram esses alumnos separados dos alumnos do quarto e do quinto anno, que ficaram sob a disciplina dos respectivos cathedraticos. O pagamento da substituição, nos termos do art. 30 do Decr. n. 3890 de I9or, foi conferido na proporção de um terço dos vencimentos; o pagamento da accumulação, visto que os professores eram de secção extranha, lhes foi conferido nos termos do art. 50 do Decr. n. I232 F de 2 de Janeiro de $\mathrm{I} 89 \mathrm{I}$, isto é, na proporção de dous terços dos vencimentos da cadeira. Aproveitei, para estes pagamentos, o saldo das taxas.

Tambem pelo saldo destas taxas mandei pagar as despezas do concerto do edificio, que importaram em $5: 464 \$ 800$, até que, si fôr verificado saldo da subvenção para o material, no corrente anno, seja possivel transferir para conta deste saldo.

Tambem pelo saldo destas taxas ha o plano de completar a reencadernação de muitos livros antigos, excellentes e alguns até raros, existentes na Bibliotheca.

Em summa, segundo a demonstração do Thesoureiro, o resto das taxas de frequencia, até hoje, é de 8:I7I\$037, e o resto das taxas de inscripção para exames é de $46: 270 \$ 936$.

\section{TITULO III}

\section{RESULTADO FINAL}

O proprio Conselho Superior de Ensino, na sua primeira reuniăo (Agosto de IgII), reconheceu:

I. $^{\circ}$ - Que a personalidade juridica, conferida pela Lei Organica ás duas Faculdades de Direito de São Paulo e do Recife, ás duas Faculdades de Medicina da Bahia e do Rio de Janeiro, á Escola Polytechnica do Rio de Janeiro, e ao Gymnasio D. Pedro II, - não lhes tira o caracter de fundações creadas, instituidas e constituidas 
pelo Estado Federal, que compoz e dispoz os orgams, especificou e distribuiu as funcções, e determinou as condições de vida;

2..$^{\circ}$ - Que, por conseguinte, as contas desses Institutos, não estando subordinadas, como as das fundações privadas a que se refere a Ordenação L. I. ${ }^{\circ}$ tit. 62 , á verificação judiciaria pelo Juizo da Provedoria, hão de ser irreductivelmente prestadas administrativamente segundo as regras da contabilidade fiscal.

Mas, a Congregação desta Faculdade, quando approvou o parecer de 6 de Maio de I9II, comquanto contemporisando com a theoria da "entidade mixta», segundo a analogia applicada ás Universidades francezas, italianas e allemãs,- tornou textualmente bem sensivel que, tal como acontece naquellas Universidades, - «a personalidade juridica, assim derivada de um acto da vontade do Estado, vem a ser um orgam do Estado».

O Director desta Faculdade dirige, pois, uma fundação do Estado Federal. Toda a administração da cousa alheia é um mandato que só póde ser conferido pelo proprietario: a autonomia administrativa do mandatario, mesmo nos mandatos geraes está subordinada ás necessidades do negocio ou cousa do mandante, isto é, si conditio et ratio administrandi id flagitet, diz o Digesto, L. 6o, paragrapho $44^{\circ}$, tit. de mandat. Mas, quando o mandato não é generico e sim individuado, o mandatario não tem nem mesmo póde ter autonomia alguma. Dahi decorre a razão por que, na contabilidade fiscal, ha uma prestação de contas em cada Ministerio (a ủos mandatos geraes) e uma prestação de contas no Ministerio da Fazenda (a dos mandatos individuados).

Tenho necessidade de repetir estes principios, para mostrar que os Institutos Federaes de Ensino Superior devem prestar as suas contas:

a) Perante a Directoria de Contabilidade do Ministerio da Justi̧̧a e Negocios Interiores, na parte relativa 
á receita especial proveniente dos proprios Institutos e á despesa de que elles têm autonomia administrativa.

b) Perante a Directoria Geral de Contabilidade do Thesouro Nacional, isto é, no Ministerio da Fazenda, na parte relativa á receita geral com applicação á despesa individuada em lei, quer quanto ao pessoal, quer quanto ao material, despesa essa em que os Institutos não têm, nem podem ter autonomia alguma, mesmo porque, relativamente a taes despesas, o proprio Ministerio da Justiça e Negocios Interiores não tem autònomia.

O proprio Ministerio da Justiça e Negocios Interiores tornou isso bem sensivel no Decr. de 5 de Março do corrente anno, expedindo o regulamento para concessão e fiscalização das subvenções. Neste Decreto, no art. $7 .^{\circ}$, se determina que compete ao Ministerio da Justiça e Negocios Interiores, pela Directoria de Contabilidade da sua Secretaria, a acção fiscalizadôra do emprego das subvenções de que trata o art. $8 .^{\circ}$ da Lei n. $273^{8}$ de 4 de Janeiro do corrente anno, e a respectiva tomada de contas; mas, no art. 9. ${ }^{\circ}$, declara expressamente as verbas de despeza de applicação legitima da subvenção, excluindo dellas as despezas feitas com o pessoal superior da admistração. Todo esse Decreto, em seu contexto e em seu espirito, revela que elle não tem applicação ás fundações officiaes; o art. $4^{\circ}$ expressamente se restringe aos «institutos não fundados pela União». Isso significa que, tratando-se de institutos fundados pela União, prevalecem as regras geraes da contabilidade fiscal.

Afinal, a verdade é que ainda não está revogado o art. I3 da Lei de 8 de Outubro de 1828 , que firmou a seguinte regra: "Todas as repartiçóes, por onde se despendem dinheiros publicos, prestarão contas ao Thesouro Publico das despezas a seu cargo; ficando responsavel o Ministro da Fazenda por sua omissão a este respeito». Foi essa a razão que me levou a aconselhar o Thesoureiro desta Faculdade a provocar uma solução da Dele- 
gacia Fiscal sobre o destino do saldo da verba-suóvençâo, não applicado ás consignações da lei, tanto mais quanto - Thesoureiro, muito regularmente, exigiu de mim a declaração de lei que mandasse incorporar esse saldo ao patrimonio da Faculdade. Ora, não ha lei alguma, que eu saiba, ordenando essa incorporação; e, por maior que seja o meu respeito ao parecer dos meus collegas do Conselho Superior, não posso thes reconhecer competencia legislativa, maxime envolvendo responsabilidade fiscal.

Quanto ás taxas de frequencia e de inscripção para exames, essas não pódem ser aproveitadas para a conversão, porque, segundo ficou definido pelo Conselho Superior, pertencem respectivamente aos professores; e a parte que não teve esse destino será aproveitada, nos termos do Aviso n. 4II de 26 de Março de I9I2, para despesas não contidas no credito ordinario da verba-subvenção. Portanto, só pódem ser aproveitadas para a conversão as taxas de matricula e de certidões e as porcentagens das taxas de frequencia e de inscripção para exames.

Desta exposição resulta que, até hoje, em dois exercicios e meio, só é possivel definitivamente destinar á conversão, en titulos de renda perpetua, para o patrimonio desta Faculdade, a quantia de 56:306\$719.

Esses titulos, si forem apolices da divida publica, renderão, no maximo, cinco por cento. Para a pretendida desofficialisação completar-se, será necessario que os rendimentos correspondam, pelo menos, á despeza actualmente orçada, isto é, a 49r:680\$ooo. São necessarios, portanto, titulos no valor de 9.834:000\$ooo, isto é, 9834 apolices.

Ora, na melhor hypothese, calculando a media dessas taxas e porcentagens, aproveitaveis para conversão, em 30:000 $\$ 000$ por anno, isto é, 30 apolices por anno, precisaremos de 328 annos para attingir 9834 apolices. E, assim, para completar-se a desofficialisą̧ão, nos termos do cit. art. I4 da cit. Lei de 4 de Janeiro do corrente anno, esta 
Faculdade ainda terá mais de tres seculos de officialisação... incompleta...

Sempre que o Estado tentou desonerar-se dos Institutos de Énsino por elle creados ou mesmo simplesmente conservados, teve de capitular, isto é, teve de retomar o encargo. Assim aconteceu em França, onde Guizot, como diz Liard, "no mesmo anno em que proclamou a personalidade civil da Universidade, incorporou ao orçamento do Estado o orçamento até então independente da Universidade»; assim aconteceu na Italia, onde, como diz Meucci, «o regio decreto de $I 7$ de Fevereiro de $185^{2}$ attribuiu ao Ministerio das Finanças a administração dos immoveis, creditos e de todas as rendas das Universidades» até que em 1872 , ficou ás Universidades «uma administração inherente»; assim aconteceu na Allemanha, onde (como consta da compilação feita, em I87I por ordem do nosso Ministerio do Imperio, sobre a instrucção publica na Prussia, por Joaquim Teixeira de Macedo, pag. 2 I7) - «a administração dos fundos das Universidades tem sido entregue aos empregados fiscaes do ministerio», de sorte que alli, em qualquer hypothese, o Esstado é o "thesoureiro das Universidades» e estas são «estabelecimento do Estado» (pag. 87).

Assim acontecerá e até já está acontecendo no Brazil, onde sem embargo do Aviso de 28 de Setembro de I9II, - Poder Legislativo, no art. I4 da Lei de 4 de Janeiro do corrente anno, declara que os Institutos federaes ainda não estão desofficialisados. Afinal, a capitulação ha de ser completa. Quem viver,-verá.

Faculdade de Direito de São Paulo, 3I de Julho de I9I3.

$$
\mathrm{O} \text { director }
$$

JoÃo Mendes de Almeida Junior. 


\section{ANNEXO}

Consolta sobre o destino do SAldo da subvenção

«Thesouraria da Faculdade de Direito de São Paulo, em 6 de Março de rgI3. Remetto a v. exa. a demonstração do saldo existente da parte da subvenção entregue a esta thesouraria, afim de pagar o pessoal docente e administrativo nomeado na vigencia da Lei Organica e para o exercicio encerrado em 3I de Dezembro de I9I2. Da quantia de 31:799\$996 foi applicada a importancia de 21: $549 \$ 978$, de sorte que ha um saldo de ro:250\$or 8 .

«Esse saldo, segundo me parece, é devido a terem sido incluidos no calculo os vencimentos dos lugares vagos de professores extraordinarios effectivos.

"Consulto a v. exa. si devo recolher esse saldo á Delegacia Fiscal do Thesouro Nacional neste Estado, ou consideral-o como incorporado ao patrimonio da Faculdade.

«Necessito acautelar a minha responsabilidade para qualquer effeito futuro; e, nestas condições, peço a v. exa. que, si entender que esse saldo deve ser incorporado ao patrimonio da Faculdade, se digne indicar-me a lei em que se funda, porque não devo arriscar-me a qualquer reclamação do Thesouro Nacional.

«Saudações a v. exa. O thesoureiro Honorio de Castilhos». 


\section{I}

«São Paulo, 29 de Março de I9r3.--Sr. Thesoureiro - Respondo á consulta que faz sobre o destino do saldo da consignaęão para vencimentos do pessoal docente e administrativo, nomeado na vigencia da Lei Organica, para o exercicio de rgr 2.

Transmittindo-lhe copia do officio que, sobre o assumpto, me dirigiu o exmo. sr. Presidente do Conselho Superior do Ensino, devo chamar a sua attenção para o seguinte:

I. - Que o Presidente do Conselho Superior do Ensino não quiz dar resolução propria, preferindo reportar-se ao parecer n. I 2 de uma commissão do Conselho Superior do Ensino, na qual se resolve: $1 .^{\circ}$ que as sobras das rendas annuaes dos Institutos serão empregadas em titulos da divida publica; $20^{\circ}$ que, entre as rendas dos Institutos, além das taxas, porcentagens, vendas de programmas, etc., se acha a subvenção votada pelo Congresso Nacional;

2.0 - Que esta segunda affirmação não corresponde á realidade, porque a subvenção tem applicação directa e immediata e, por isso, não póde ser considerada renda, isto é, producto ou resultado de capital dos Institutos;

$3 .{ }^{\circ}-$ Que, por mais respeitavel que seja a autoridade do Conselho Superior do Ensino, a sua interpretação, além de simplesmente doutrinal, não é applicavel a casos que possam envolver responsabilidade fiscal;

$4 .^{\circ}$ - Que os vencimentos são arbitrados pelo "proprio» Estado, para "cada um» dos cargos, de sorte que, seja como fôr, o pagamento é uma consignação do Estado, destinada a cada um dos funccionarios individuados pelo mesmo Estado;

$5 .^{\circ}$-Que si, por contemporisação, cada um desses vencimentos não tem sido averbado na Delegacia Fiscal do Thesouro Nacional, essa irregularidade se afasta dos principios e regras da Fazenda Nacional; 
6. ${ }^{\circ}$ - Que a Fazenda Nacional ha de fatalmente averbal-os, para que entrem nos moldes inflexiveis da arithmetica e contabilidade da mesma Fazenda; $\left({ }^{*}\right)$

$7 .^{\circ}$ - Que, portanto, a Fazenda Nacional ha de, mais cedo ou mais tarde, reclamar a restituição de tudo que, da subvenção, não tenha sido applicado ao fim peculiar a que se destina;

$8 .^{\circ}-$ Que, sendo o Thesoureiro desta Faculdade pagador de uma consignação do Esstado, está fiscalmente responsavel, cumprindo-lhe, como necessaria cautela, provocar directamente uma resposta categorica do Delegado Fiscal do Thesouro Nacional, já que o sr. Ministro da Justiça e Negocios Interiores não quer corresponder-se com esta Directoria e já que o sr. Presidente do Conselho Superior do Ensino não quer, por si, assumir a responsabilidade da solução da consulta. - O director, (a) João Mendes de Almeida Junior.--Sr. dr. Honorio de Castilhos, M. D. Thesoureiro da Faculdade.»

\section{I}

«S. Paulo, 5 de Abril de rgr3. - Illmo. sr.-Declaro a v. s. que, da parte da verba a que se referem o artigo 2..$^{\circ}$ e paragrapho unico da $J_{1}$ ei do Orçamento $n$. 2.544, de 4 de Janeiro de I9I2, consignada para pagamento, nesta thesouraria, dos professores e funccionarios nomeados na vigencia da Lei Organica do Ensino, ha uma

(*) Fiz deduzir o imposto do sello do meu titulo de Director, nos termos do Decr. n. 3564 de 22 de Janeiro de 1900, art. 10.0, $\$ 1.0$ e tabella A, $\$ 80^{\circ}$, isto é, $910 \$ 000$, em descontos de 12 prestacóes mensaes, $5,5 \%$ sobre o total dos vencimentos, e o restante de uma só vez.

Faço deduzir tambem o imposto sobre vencimentos, nos termos do arts 1.0 e 20 do Decr. n. 7544 de 22 de Novembro de 1879. Essa arrecadação, na Delegacia, era feita pela folha; mas, não tendo sido, apezar da minha requisiçāo, averbado alli o meu titulo, mandei averbal-o na Thesouraria desta Faculdade, ad instar do modelo adoptado na Thesouraria de Fazenda. 
sobra de dez contos duzentos e cincoenta mil e dezeseis réis (I0:250\$0I6).

Tratando-se de uma consignação do Estado Federal para pagamento de professores e funccionarios, cujos cargos e empregos estão discriminados na lei, e até providos por nomeação do Governo, consultei o Director desta Faculdade si devia incorporar aquelle saldo ao patrimonio do Instituto, ou devolvel-o a essa Delegacia, não obstante deixar de ser feita ahi a averbação peculiar, determinada pelo Decreto de 23 de Dezembro de I909, assim como por outras Leis e Regulamentos fiscaes.

O Director desta Faculdade, depois de haver, por sua vez, consultado o Presidente do Conselho Superior do Ensino, declinou de dar uma solução categorica e aconselhou-me que requisitasse de $v$ s. essa solução, visto que, a seu ver, tratando-se de uma consignação do Estado Federal e portanto do Thesouro Nacional, para pagar vencimentos numerados em lei, a funccionarios determinados em lei e que exercem funç̧ões especificadas em lei, eu estou fiscalmente responsavel pela applicação desse peculiar destino.

Por outro lado, o Presidente do Conselho Superior do Ensino declarou que, segundo a doutrina do Aviso de 28 de Setembro de I9II, os titulos desses funccionarios não estão sujeitos á averbação fiscal, de sorte que qualquer sobra dessa consignação deve ser incorporada, como renda, ao patrimonio da Faculdade, para ser convertido em titulos da divida publica.

Necessitando acautelar a minha responsabilidade, requisito de v. s. se digne solicitar do Ministerio da Fazenda uma solução categorica, que, em relação a esse ponto, afaste de mim qualquer responsabilidade para 0 futuro.

Como v. s. sabe, o Director desta Faculdade assignala: 
I. Que, a obrigação de pagar o pessoal desta Faculdade, individuado em lei, quer 'o antigo, quer o novo, é «unica e incommunicavel» do Estado Federal e, portanto, do Thesouro Nacional;

2. Que, já desde o Alvará de 28 de Junho de r 808 , titulo $4 .^{\circ}$, n. 4 , e titulo $70^{\circ}$ ns. 4 a 7 , tratando-se de vencimentos taxados em lei, para cargos ou empregos creados por lei e funcęões definidas por lei, torna-se irreductivelmente necessario averbar annualmente pelo Thesouro, na respectiva folha de pagamento, o nome do funccionario, a lei especial que fixa os vencimentos, a lei do orçamento, que determina o credito, a distribuição mensal do ordenado e gratificação, o imposto, as faltas e as substituições;

$3 .{ }^{\circ}$ Que, estas regras, firmadas em todos os posteriores Regulamentos fiscaes, especialmente desde o Regulamento de 20 de Junho de 1840 (terminantemente mandado applicar, até em seus modelos, ás thesourarias de Fazenda pelo Decreto n. 870 de 22 de Novembro de I85I, artigo $\mathrm{I}^{\circ}$, paragrapho ro, e Instrucções de ro de Dezembro desse mesmo anno, artigo 9) foram desenvolvidas pelo Decreto n. 7.75 I de 23 de Dezembro de I909, artigo 318 e seguintes, e são unico meio de verificar a applicação das leis que fixam os vencimentos e o pagamento segundo a effectividade do exercicio.

$4^{\circ}$ Que, portanto, as subven‡̧ões para pagar vencimentos numerados em lei a funccionarios determinados em lei e individuados até por nomeação do Governo, importa uma consignação fatalmente individual, a qual, na forma das leis fiscaes, não póde deixar de ser, discriminadamente e em cada exercicio financeiro, averbada pelo Thesouro como titulo peculiar de despesa.

Ora, tendo a Congregação da Faculdade, nestes pontos, solemnemente se declarado solidaria com o Director, nem mesmo posso provocal-a para outra solução.

Os vencimentos dos professores nomeados na vigencia da Lei Organica são os mesmos numerados pela 
lei n. ${ }^{\circ}$ I 500 de I de Setembro de I906; e conforme a determinação dessa lei, abri aqui, para cada um delles, a folha de pagamento, "ad instar» da averbação que antes era feita nessa Delegacia.

Notarei a v. s. que os referidos professores allegam:

I. $^{\circ}$ Que, recebendo os seus vencimentos nesta thesouraria, continuam a recebel-os do Thesouro Nacional, visto que a thesouraria desta Faculdade é uma simples intermediaria;

2. Que, por conseguinte, deve-lhes ser descontado, nesta thesouraria da Faculdade, não só o imposto sobre vencimentos, como as contribuições para Montepio, tanto mais quanto dois delles, no exercicio de I9I2, tiveram os seus titulos averbados na Delegacia Fiscal, em folha de pagamento, sendo-lhes ahi descontados o sello de nomeação, imposto sobre vencimentos, «ex vi» do decreto n. 7.544 de 22 de Novembro de I879, artigo I. ${ }^{\circ}$ paragrapho $2 .^{\circ}$ e contribuição para o Montepio obrigatorio, «ex vi» do artigo r. ${ }^{\circ}$ do decreto n. ${ }^{\circ} 8.904$ de 16 de Agrosto de I9II;

$3^{\circ}$ Que o Aviso de 28 de Setembro de I9II nem mesmo póde referir-se a elles, visto que usa da locução "professores auxiliares», que não póde ser applicavel a «professores effectivos», como elles o são.

Conforme resolução do Conselho Superior do Ensino, terei de descontar o imposto sobre vencimentos e a contribuição do Montepio; feito esse desconto, deverei recolher a essa Delegacia a respectiva importancia. E, assim, tambem consulto a v. s. em que termos deve ser faita a guia para o recolhimento desses descontos do imposto de vencimentos e da contribuição do Montepio, uma vez que, não sendo averbada ou aberta ahi a folha individual de pagamento, a deducção só poderá ser feita na thesouraria desta Faculdade.

Illmo. sr. Felinto Elysio do Nascimento, m. d. Delegado Fiscal do Thesouro Nacional. - O thesoureiro da Faculdade de S. Paulo, Honorio de Castilho.s 